\title{
O DESAFÍO DA CALIDADE NA COMUNICACIÓN
}

\author{
Fermin Galindo Arranz
}

Universidade de Santiago de Compostela

A transmisión da noticia e a súa velocidade perderon centralidade no debate comunicacional dos últimos tempos, ata o punto de chegar a se converter esa mesma instantaneidade nun hándicap do propio sistema informativo. A veracidade da información e o crédito dos medios conforman os eixes centrais do novo concepto de calidade ligado á comunicación, un reto importante ao que convén prestar tempo e atención no debate público sobre os desafíos actuais da comunicación.

\section{COMUNICACIÓN E CALIDADE}

A avaliación e o control da calidade é hoxe unha das principais preocupacións en todos os sectores produtivos. Nos últimos anos estendeuse a cultura empresarial da calidade en Europa a partir da premisa de que producir mellor rende máis beneficios e, por tanto, garante o futuro da empresa e dos postos de traballo ${ }^{1}$. Desde un punto de vista economicista o control de calidade aplicado aos sistemas produtivos e á prestación de servizos busca una serie de condicións que garantan idoneidade, eficiencia e calidade. En España chegouse á cultura da calidade con certo atraso. A partir da entrada na Comunidade Europea -o 1 de xaneiro de 1986- e desde entón traballouse contra reloxo, polo que en certa medida aínda se mantén certo impulso inicial.

Os grupos empresariais e as pequenas e medianas empresas que traballan no ámbito da comunicación non son alleas a esta corrente. Pero tamén convén resaltar que falamos dun sector característico pola súa singularidade. As empresas informativas tamén participan nesta tendencia de procura da calidade pero atópanse ante a dificultade para a súa posta en práctica debido á súa dobre

1. Ver declaracións de Manuel López Cachero, presidente de AENOR (Asociación Española de Normalización y Certificación), a La Voz de Galicia, suplemento «Mercados», 10/10/2004, p. 5. 
faceta de traballo industrial e seriado por unha parte e ao seu carácter creativo e especialmente sensible ao contorno e ás intromisións e intervencións no ámbito das liberdades e dereitos fundamentais. E é aquí onde radica o desafío da calidade na comunicación, na capacidade para reunir, dalgunha maneira, de forma conxunta ambas as circunstancias.

Este dilema non é privativo da comunicación. Santiago López Torrado ${ }^{2}$ introdúceo con acerto no ámbito da educación:

Es preciso delimitar con cuidado el concepto de calidad, ampliamente manejado con distintas finalidades y connotaciones y que conviene discernir dada su relativa ambigüedad. Hoy se pide calidad para todos y para todo, se habla de «calidad de vida», «calidad de educación», etcétera. Precisamente esta última- y las características que se le atribuyen -nos sirve de cautela para nuestro propósito de discernir la calidad. Al concepto de calidad educativa se le reviste habitualmente de notas de elitismo, competitividad, esfuerzo personal, eficacia y pragmatismo, que no son las más adecuadas para definir el concepto auténtico de calidad.

Algo parecido poderiamos dicir noutros terreos, entre eles o da comunicación.

Como vemos, o autor de «El valor de la calidad» presenta unha lectura completamente diferente do termo calidade, que encadra desde a pedagoxía no «horizonte de sentido que orienta a nosa vida e as relaciones humanas e sociais». Así argumenta, en sentido contrario ao concepto economicista de calidade, que a calidade ten relación, nalgunha medida, co talento. Existen diversas clases de talento: poético, contemplativo, profético, irónico... Desde este punto de vista, o concepto de calidade asóciase ao talento e á expresión artística e ten unha relación directa co ámbito da comunicación e as súas diferentes disciplinas, nas que a creatividade, a empatía, ou a solidariedade -só por citar algúnsson valores de referencia na súa práctica profesional.

2. López Torrado, S. «El valor de la calidad». El País, Madrid, 24/5/2004, p. 41. 
López Torrado non asocia o talento á fama ou ó éxito, aínda que afirma que poden coincidir ${ }^{3}$.

Ni el talento ni la calidad son necesariamente la «excelencia», ni el refinamiento o elitismo como concepción o práctica de la vida. La sofisticación y la falta de sencillez no adornan precisamente la calidad, sino más bien al contrario. En cambio, sí que tiene mucho que ver con la calidad, con el trato humano racional, con la acogida cálida entre las personas, con el ejercicio riguroso del pensamiento y del diálogo, con la gratuidad, con la contemplación desinteresada de la belleza en sus distintas formas, con la generosidad y con el trabajo por los demás.

É dicir, asocia a «calidade educativa» aos valores, ideas e actitudes sobre as que se asenta esta con trato humano racional, coa acollida cálida entre as persoas, con exercicio rigoroso do pensamento e do diálogo.

Pero a calidade na comunicación non só depende dos valores sobre os que se sustenta a actividade dunha organización, depende doutros factores. Así, o crecemento exponencial da capacidade tecnolóxica para a transmisión de noticias perdeu centralidade no debate comunicacional, e este trasladouse a novos conceptos. Incluso a propia instantaneidade da comunicación se converteu nun desafío para a credibilidade do propio sistema informativo. Algúns acontecementos recentes ligados a estratexias de desinformación orquestradas desde o poder sobre o contorno dos medios amosaron a vulnerabilidade destes últimos e os seus contidos como produtos de calidade. A ansiedade cidadá pola procura dunha información fidedigna fronte aos intentos de manipulación evidenciou a indefensión do público fronte a estas prácticas, en maior ou menor medida, en todos os soportes. Desta forma, a veracidade da información e o crédito dos medios de comunicación conforman os eixes centrais dun novo concepto de calidade ligado ao ámbito do periodismo e a información.

3. Talvez o éxito de crítica e público de Alejandro Sanz sexa exemplar do concepto de calidade aplicado ao ámbito da comunicación audiovisual actual. 
Este debate non é novo nas ciencias sociais, así hai xa tempo que os institutos demoscópicos e as empresas de investigación de mercados se atoparon coa necesidade de establecer infraestruturas de control dos seus traballos de campo co fin de garantirlles aos seus clientes a calidade dos resultados obtidos ${ }^{4}$. A formación e especialización dos traballadores, a creación de institucións arbitrais e de órganos colexiados ou a autorregulación eran e son inquietudes compartidas polas empresas do sector que agora se mimetizan desde as empresas informativas.

Noutras ocasións teñen sido as propias organizacións informativas as que fallaron con actuacións fraudulentas ${ }^{5}$, casos nos que se prescindiu da mínima ética periodística e dos mínimos principios de deontoloxía profesional. Nestas ocasións, descuberta a fraude, debe ser a propia empresa editorial a que ten que establecer os mecanismos de garantía e control de calidade do produto informativo ofertado aos seus clientes no intento de recuperar a credibilidade perdida. É dicir, debe establecer os mecanismos pertinentes de autocontrol e avaliación da calidade.

Neste sentido, desde o Departamento de Ciencias da Comunicación da Universidade de Santiago de Compostela traballamos intensamente na análise, control e garantía da calidade periodística ${ }^{6}$. Así, Bettina Kohlhaas entende, na súa tese de doutoramento sobre o tema, que o produto informativo esixe o seu propio sistema de control de calidade debido ás particularidades da súa natureza. Este depende da rede de infraestruturas de control e garantía de calidade, baseada en gran parte no autocontrol, e pre-

4. Escario, Pilar. «El control de calidad del trabajo de campo», Investigación y Marketing, AEDEMO, Madrid, n. ${ }^{\circ}$ 38, 3/1992, p. 15.

5. Nos anos noventa a revista The New Republic pasou, de forma eventual, de ser medio a obxecto de información a consecuencia do escándalo provocado por un dos seus redactores. Descubriuse que 21 das 47 historias por el publicadas eran froito da súa imaxinación. Este caso foi levado en datas recentes á gran pantalla e estreado en español co título El precio de la verdad, nel cóntase un rechamante caso de procura do éxito periodístico polo camiño máis curto.

6. Ver a tese de doutoramento de Bettina Kohlhaas, Aproximación al concepto de control y garantía de calidad en prensa. El caso de La Opinión de A Coruña (Grupo Editorial Prensa Ibérica), pp. 23-24. 
séntase como unha opción que servirá para fomentar o debate da calidade na comunicación.

A partir do enfoque teórico desenvolvido polo catedrático da Universidade Libre de Berlín, o profesor Stephan Russ-Mohl, que combina a teoría de sistemas con reflexións sobre bens públicos, sistematizamos a rede de infraestruturas da comunicación a partir de tres momentos. Un primeiro momento previo á elaboración da noticia, un segundo lugar, durante o proceso de produción e elaboración da noticia, e un terceiro tempo de feedback ou retorno das informacións publicadas. As medidas poden ser, polo tanto, preventivas, paralelas e correctoras ou de retorno, dependendo do tempo de actuación. Ademais, distínguense medidas internas, externas e de diálogo cos receptores.

As medidas internas confórmanas todas as iniciativas dos profesionais da información encamiñadas a garantir algún aspecto da calidade do produto informativo. As medidas externas son aquelas ferramentas que contribúen á mellora da calidade do produto alleas ao ámbito estritamente periodístico. Neste terreo o marco legal adquire unha importancia decisiva por ser o garante non só das liberdades fundamentais, senón tamén dunha comunicación de calidade. Finalmente as medidas de diálogo co público, os esforzos conxuntos en prol da calidade que brota entre os medios e as súas respectivas audiencias. Polo tanto, esta rede de infraestruturas é entendida desde esta perspectiva como unha auditoría de calidade mixta que recicla medidas de autocontrol, fundamentalmente existentes no mercado con fins de mellora e garantía de calidade.

\section{O TELELIXO COMO PARADIGMA DE NON CALIDADE}

No balance da última tempada televisiva de El Anuario de la Televisión en España, José Ramón Pérez Ornia e Santiago Gómez Amigo $^{7}$ asocian o termo telelixo ao xornalismo rosa e á sobreexplotación televisiva dos reality-shows. E destacan o incremento deste tipo de programas na última década. En 1993 unicamente se

7. Director e subdirector da publicación. Ver El anuario de la Televisión 2004, Geca, Madrid, 2004, p. 12. 
emitía Corazón Corazón en TVE e dez anos máis tarde só as tres grandes cadeas xeneralistas programan máis de 30 horas sobre o tema entre programas independentes e seccións de diferentes espazos. Tamén sinalan como as críticas pola presenza na programación chegan ás súas máis altas cotas de forma paralela ao seu éxito de audiencia e tamén ao da súa conta de resultados. Así os programas coñecidos como telelixo son superrendibles na relación prezo-audiencia. Mentres que o custo dun capítulo dunha serie de produción española é de 6000 euros por minuto, o custo dun reality-show ou dun programa do corazón rolda os 300 euros por minuto. Un plató, un presentador e uns cantos invitados serven para organizar unha liorta tan rendible como pouco edificante. Xa que logo, talvez o exemplo máis estendido de non-calidade sexa o que se encerra ou se sobreentende coa expresión telelixo.

E que é o telelixo? Para o escritor Antonio Galas:

Todo el mundo sabe lo que es. Sin confundirla con la falsedad política. No sólo los vulgares chismes, autoadjudicados o no, con montajes o cámara ocultas, que sólo les interesan a los que ya llevan la basura dentro, o viven de las vidas ajenas por no tener una propia, sino la de los encerrados, y luego sueltos, en casas de hermanos más o menos pequeños, en granjas o en islas o en planetas, donde se vocifera, se ensucia el sexo, se prodiga una asquerosa sensiblería, se representan papeles despreciables, se hunde la dignidad... Y también aquélla en que la maldad y la violencia sin sentido enseña a los niños un mundo que han de hacer diferente. No se puede matar en ellos ni en nadie la ilusión, la limpia alegría, la esperanza y la fe humana. Ni por hacerse seudofamosos. Ni por ganar dinero. Ni individual ni empresarialmente.

O anterior comentario non é máis ca un máis sobre o tema, que centrou o interese da opinión pública nas últimas semanas ${ }^{9}$.

8. Gala, A., ver «Telebasura», en La Tronera nas páxinas de El Mundo, Madrid, 30/02/2004, p. 13

9. Cando escribimos estas liñas os principais buscadores (Yahoo, 85 300; Altavista, 85 000; Ariadna, 9139; MSN, 9141...) ofrecen miles de entradas co termo telelixo; só Google, o máis utilizado, oferta máis de 32000 referencias a telelixo, cun incremento espectacular nas últimas datas. 
O crítico de televisión José Miguel Giráldez ${ }^{10}$ intentaba dar resposta a esta pregunta.

El director de Gran Hermano, Roberto Ontiveros, viene de decir en una conferencia en La Rioja que nadie puede definir telebasura, por mucho que se hable de ella. O sea, que no se sabe bien que es la telebasura, ni cuáles son sus límites. Ontiveros, que tenemos la televisión que nos merecemos, y, sobre todo, la tele que pedimos. Vamos, vamos, Dudo mucho que la audiencia sea siempre la culpable, sobre todo porque Caffarel ${ }^{11}$ ha huido de los Realities (afortunadamente) y dice todo el rato lo mismo que Ontiveros: «la televisión que tú pides» $»^{12}$.

E é que tamén hai moitos que piden calidade. Entre eles, o Defensor do Pobo, Enrique Múgica ${ }^{13}$; na súa opinión: «telebasura es un acertado término para muchos de los programas que emiten las televisiones en horario infantil, con imágenes de violencia, degradación, crueldad, difamación y palabras soeces». E entende que se debe respectar «el derecho del niño a recibir una educación digna, que le inculque valores profundos y a que la programación televisiva no los conculque».

O chamado telelixo non só é un tema recorrente, sinalan Pérez Ornia e Gómez Amigo ${ }^{14}$, senón que as críticas pola súa presenza na programación foron unha constante nos últimos anos. A superabundancia de información rosa, tratada con estilos e formas que se reproducen mimeticamente, evidencia por outra banda o conservadorismo da programación, a falta de innovación e a impresión de que, no canto de pluralidade e diversidade de ofertas, emítese, como se chama nos medios, «máis do mesmo». Ata os últimos presidentes do Goberno, José María Aznar e José Luis Rodríguez Zapatero, criticaron o fenómeno do telelixo con reitera-

10. Giráldez, J.M. «E que é a telebasura?», O Correo Galego, Santiago, 11/11/2004, p. 70.

11. Directora xeral de RTVE.

12. Slogan publicitario da cadea durante o verán de 2004.

13. Ver declaracións recollidas por El Mundo, «Protección do menor ante a televisión», Madrid, 26/10/2004, p. 60.

14. Ver El anuario de la Televisión 2004, Geca, Madrid, 2004, p. 12. 
das e persistentes declaracións neste sentido. As máis recentes ${ }^{15}$, realizadas por este último, eran levadas á primeira do diario El País: «Se as televisións non regulan os seus contidos, o Goberno actuará». Hoxe en día, só as tres grandes cadeas emiten a diario máis de trece horas de rexouba e telenovelas en horario infantil ${ }^{16}$.

Desde Galicia e nas mesmas datas, o director de La Voz de Galicia, Bieito Rubido, reclamaba dos medios públicos unha contraprogramación de calidade, en concreto sobre a practicamente inexistente programación televisiva infantil ${ }^{17}$. Asunto este de interese transcendente e que adoita caer en lecturas apocalípticas sobre a súa influencia e perversidade, e que de cando en cando recibe unha pormenorizada análise como a titulada expresivamente «Como acabar co telelixo no horario infantil», que asinaba Carmen Chacón e na que pedía o cumprimento estrito da lei logo dunha concienciuda argumentación a partir do telelixo emitido nas tardes dos últimos meses e reclamando diferentes medidas.

Ademais da Constitución existe unha directiva europea ${ }^{18}$ en vigor que establece que entre as 6.00 e as 22.00 non se poden emitir contidos que prexudiquen aos menores. Nos mesmos termos e con similar argumentación fóronse expresando publicamente: o Defensor do Menor de Madrid, as principais asociacións de telespectadores, consumidores e defensores da infancia. Neste sen-

15. Publicadas o 17 de outubro de 2004 e entresacadas dunha ampla entrevista con José Luis Rodríguez Zapatero.

16. Gómez, R.G. «Los poderes de la "telebasura"», El País, Madrid, 31/10/2004, p. 40.

17. Declaracións realizadas na mesa «Medios de comunicación e infancia» celebrada en Santiago o 9 de outubro de 2004 e na que participaron Javier Otero, director da Cadena Ser en Galicia, José Manuel Rey Novoa, director de O Correo Galego, Alfonso Sánchez Izquierdo, director de La Región, e Xoán Manuel García, director da AGN. Todos eles mostraron a súa preocupación e sensibilidade por dedicar desde os medios unha programación de calidade dirixida á infancia.

18. A Directiva de Televisión sen Fronteiras 89/522/CEE, incorporada ao Ordenamento Xurídico Español coa Lei 25/1994, do 12 de xullo, e ao resto dos países da Unión Europea. A Lei de 1994 é clara respecto diso: «A emisión de programas susceptibles de prexudicar o desenvolvemento físico, mental ou moral dos menores só poderá realizarse entre as vinte e dúas horas do día e as seis horas do seguinte, e deberá ser obxecto de advertencia sobre o seu contido por medios acústicos e ópticos». 
tido, o Defensor do Pobo, Enrique Múgica, logo de entrevistarse coa vicepresidenta primeira do Goberno, María Teresa Fernández de la Vega ${ }^{19}$, responsabilizou os programadores da situación actual e apostou por dar un prazo ás televisións para que eliminen do horario infantil o telelixo e considerou que, se tras ese período se comproba que a autorregulación non funciona, o Goberno debe obrigalos a respectar a Constitución e as leis. É dicir, os axentes sociais desconfían inicialmente das medidas internas das propias televisións, dos seus programadores e da sinceridade das súas intencións. En expresión do propio Enrique Múgica: «se teme que la autorregulación sea tan solo una cortina de humo» ${ }^{20}$.

O crítico de televisión Sergi Pámies advertía neste sentido:

Paolo Vasile, consejero delegado de Tele 5, afirma que su cadena establecerá «norma de sentido común» para controlar los contenidos que se emiten en horario infantil. Pobre sentido común. Pobres niños. Este debate sobre contenidos y continentes, mezclados con la futura concesión de nuevos canales y sus secuelas bursátiles, suena más a batalla empresarial que a reforma. El elemento de distracción es la moralidad, pero, como en la magia, el truco está en otra parte y lo controla quien consigue que permanezcamos más hipnotizados que atentos a la pantalla. Se cambian los contenidos pero no sus mecanismos de distribución ${ }^{21}$.

En resumo, á vista da insuficiencia das medidas internas para abordar a cuestión xustifícase a adopción de medidas externas que incidan sobre o sistema televisivo no seu conxunto.

Entre as medidas externas contémplanse fundamentalmente as iniciativas lexislativas; ademais da aplicación da lexislación vixente susceptible de ser corrixida e ampliada con novas normas xurídicas ou o esperado informe do "comité de sabios» sobre a televisión pública. Neste sentido «ya se ha adelantado que las propuestas esenciales de ese informe serán las que inspiran un pro-

19. Ao longo do mes de outubro de 2004, o Goberno mantivo unha rolda de contactos cos interlocutores sociais sobre a protección da infancia fronte ao telelixo.

20. Ver O Correo Galego, Santiago, 26/10/2004, p. 77.

21. Pámies, S. «Regulación», El País, Madrid, 24/10/2004, p. 68. 
yecto legislativo para abordar el futuro marco jurídico y financiero de la radio y televisión pública como su paso definitivo al pluralismo y la independencia» ${ }^{22}$.

Finalmente, José Luis Rodríguez Zapatero xustifica estas medidas:

Las televisiones privadas están obligadas a cumplir las prescripciones legales. El Gobierno tiene la firme determinación de que los horarios de programación infantil tienen que ser respetados de manera escrupulosa en sus contenidos. Por cierto, ésta es la denuncia mayoritaria que el Gobierno recibe de la ciudadanía.

E transmite a oportunidade de crear un organismo que garanta a coherencia do sistema e crear, como en toda Europa, un consello audiovisual que afronte estas tarefas. Neste sentido, Carmen Chacón ${ }^{23}$ destaca como «España sigue siendo hoy el único de los países de la antigua Europa de los Quince que no se dotó de un Consejo del Audiovisual independiente que vele por el cumplimiento de las misiones de servicio público que tienen confiadas todas las televisiones, incluidas las privadas». Tamén salienta capacidade para sancionar dalgúns destes organismos e de regulación sobre contidos que atenten contra a dignidade da persoa e conclúe: «Expuestas las cadenas a multas millonarias, el panorama audiovisual en estos países goza de una calidad sensiblemente superior a la nuestra».

E ata aquí chegamos no debate actual sobre a televisión como medio de referencia, o dos contidos e a súa calidade. O noso obxectivo unicamente foi apuntar a posibilidade de avaliación e control de calidade de medios e mensaxes. En síntese, observar como os mecanismos de avaliación da calidade poden axudar a alcanzar unha comunicación de éxito, nun mercado moi competitivo, con actores poderosos e dominantes, baixo a omnipresente

22. Ver declaracións do presidente do Goberno, José Luis Rodríguez Zapatero, publicadas polo diario El País nunha ampla entrevista realizada por Jesús Ceberio e Félix Monteira, Madrid, 17/4/2004, p. 21.

23. Chacón, C. «Cómo acabar con la "telebasura" en horario infantil», El País, Madrid, 9/02/004, p. 34. 
mirada da Administración, e no que o diálogo e as medidas de retorno co consumidor final deben desempeñar un papel determinante. Por iso a cidadanía debe ser consciente desta situación e saber recompensar coa súa estima, atención e confianza o exercicio dunha comunicación de calidade. En definitiva, premiar aqueles actores que sexan capaces de afrontar con éxito o desafío da calidade. 
